9 Gloucestershire County Council. Gloucestershire Local Projection 2010. Report of Research \& Development Team, Chief Executive's Support Unit. Gloucestershire County Council, 2010.

10 Department of Health. Mental Health: New Ways of Working for Everyone. Department of Health, 2007.

11 Royal College of Psychiatrists. Challenging Behaviour: A Unified Approach (College Report CR144). Royal College of Psychiatrists, 2007.

12 Darzi A. High Quality Care for All: NHS Next Stage Review Final Support TSO (The Stationery Office), 2008.

13 CSIP Choice \& Action Team. Commissioning a Brighter Future: Improving Access to Psychological Therapies Positive Practice Guide. TSO (The Stationery Office), 2007.
14 Department of Health. Confirmation Of Payment By Results For 20102011. Mental Health Clustering Booklet 2010-2011. Department of Health, 2010.

15 Department of Health. Living Well with Dementia. A National Dementia Strategy. Department of Health, 2009.

16 The Lord Laming. The Protection of Children in England: A Progress Report TSO (The Stationery Office), 2009.

17 Department for Children Schools \& Families. Children's Trusts: Statutory Guidance on Inter-Agency Cooperation to Improve Well-Being Of Children, Young People and their Families. Department for Children Schools \& Families, 2008.

\title{
An innovative service but will it work in practice? Commentary on ... Fair Horizons ${ }^{\dagger}$
}

\author{
Stephen Patrick Tyrer ${ }^{1}$
}

The Psychiatrist (2012), 36, 30-31, doi: 10.1192/pb.bp.111.036889

${ }^{1}$ Newcastle University, Newcastleupon-Tyne, UK

Correspondence to Stephen Tyrer (s.p.tyrer@ncl.ac.uk)

First received 11 Sep 2011, accepted 26 Sep 2011
Summary This commentary discusses the proposed service, Fair Horizons, a new development designed to ensure comprehensive mental healthcare coverage. Although the aims of the new service are laudable and derive from recent seminal papers on changes in the National Health Service, the proposed initiatives are so far untested and there is uncertainty about how far costs will be reduced under this new system. Success is more likely to result if clinicians are committed to the new service and work harder.

\section{Declaration of interest None.}

Despite the recent political furore about the role of general practitioners (GPs) in the implementation of the NHS Reform Bill ${ }^{1}$ the influence of GPs is legislated to increase over the coming months. Lord Darzi's preliminary review of the National Health Service (NHS) in England proposed the development of GP-led health centres. ${ }^{2}$ The aim of these centres is to provide services from GPs and consultants, with diagnostic and therapeutic services under one roof. Mental health services are an integral component of this system. The impetus for the development of Fair Horizons, a local non-discriminatory mental health service model in Gloucestershire, may partly have derived from Lord Darzi's review but was more influenced by a government paper $\mathrm{New}$ Horizons: A Shared Vision for Mental Health, introduced by the then Prime Minister Gordon Brown in 2009. ${ }^{3}$ A subsequent report from the Royal College of Psychiatrists, Mental Health and the Economic Downturn, ${ }^{4}$ resulted in the publication of an Occasional Paper, ${ }^{5}$ and the recommendations indicated in this paper underlie the initiative described.

†See Special article, pp. 25-30, this issue.

\section{New service tenets}

The proposed development stated in Fair Horizons aims to ensure equitable and comprehensive mental healthcare for all who access the service. In particular, people who have chronic mental health difficulties that no longer require specialist secondary care will be supported by appropriate mental healthcare professionals. This support is proposed to be carried out by what is termed the interdisciplinary community team, essentially an expanded and more comprehensive standard community mental health team. Although the model "provides for a "practice-based mental health team" ... based in primary care with populationbased case-loads' (p. 30), the interdisciplinary teams will not, as far as I can make out, be necessarily situated in primary care (though many may well be), but will be at the centre of a number of locality hubs that will be placed throughout Gloucestershire. The model ensures that all referrals, from primary care or elsewhere, come to the service via a first-point-of-contact centre. These centres will be staffed by administrative personnel, but all the details of the referral will be recorded on an electronic database 
and appropriate service pathways determined by means of pre-designed algorithms. Most referrals will be sent to the interdisciplinary team.

There is a sound theoretical underpinning of the new service, promoting discussion between different disciplines in the management of, for instance, people with intellectual disabilities who develop dementia, and adolescents who develop affective illnesses associated with misuse of drugs. The new service envisages that all people with mental health issues will be known and managed by the new service, which is very probably not the case at present. The authors trumpet that the new service is not discriminatory because all people referred, whatever their age or disability, will be assessed by experts in all disciplines, not just those who work within the service category to which the patient is normally assigned according to age and IQ.

\section{Remaining questions}

The model that is described is just on the point of being implemented and there are no data to indicate how it will work in practice. As is often the case with new systems that are developed to solve the faults of existing services, the benefits may not be realised in practice. There is no mention of the training of personnel involved in the service, and the potential problems of obtaining permission from regulatory bodies to enable nursing and other staff trained in other disciplines of psychiatry but not in adult general psychiatry are not discussed. There is little mention of in-patient services other than a statement that the current services would continue but 'some specialist in-patient provision for children, people with intellectual disabilities and organic mental disorders will be required' (p. 29). As the first-pointof-contact centre is going to be staffed by non-clinicians, how many referrals are likely to be directed down an inappropriate pathway? How far will it be possible for patients to receive appropriate psychotherapeutic intervention according to the Improving Access to Psychological Therapies initiative, at a time when mental health services are considerably stretched? What fraction of patients are expected to be referred to the tertiary highly specialist teams? To what extent will consultants be able to devote extra sessions to the interdisciplinary team when they already have a committed ten-session job plan? The workload of the hubs is bound to vary dependent on whether the catchment population is urban or rural but the authors state confidently that this model is able to adapt to the differing populations in Gloucestershire with similar staffing numbers.

The authors rely on the Royal College of Psychiatrists' Occasional Paper ${ }^{5}$ to indicate that the proposed service will 'drive down costs', but the cost implications of the new service are not given. With additional sessions for consultant time and extra in-patient provision the basis for assuming a cost reduction seems surprising. A sceptic could well add that when money is short more attempts are made to spur the clinician into extra activity.

\section{A word of encouragement - and caution}

The principles of Fair Horizons, namely a new strategic plan, an emphasis on clinical leadership and reform of workforce to ensure a greater contribution, have been stated recently in this journal by Louis Appleby in a different clinical context, the psychiatric care of offenders. ${ }^{6}$ I agree with Appleby when he states in discussing reform of any NHS policy that 'the crucial power lies with clinicians who have the energy and influence to make a policy work (or not)'. The proponents of Fair Horizons should heed the words spoken by Jesus in the Sermon on the Mount (Matthew 5:41). In the first century AD there was a law in Palestine that gave a Roman soldier on the march the right to challenge any passing Jewish citizen and demand that he carry his kit for a mile. Jesus wanted his followers not just to put up with this, but to go as far again voluntarily, in a spirit of charity and helpfulness: 'Whosoever shall compel thee to go a mile, go with him twain'. If Dr Fear and his co-authors are committed and a majority of his colleagues are likewise, the results of 'going the extra mile' could well be worth the effort.

\section{About the author}

Stephen Patrick Tyrer, Honorary Clinical Senior Lecturer, Newcastle University, Department of Academic Psychiatry, Newcastle General Hospital, Westgate Road, Newcastle-upon-Tyne NE4 6BE, UK.

\section{References}

1 Delamothe T, Davies E, Godlee F. Bury the bill. BMJ 2011; 343: 1-2.

2 Darzi A. High Quality Care for All: NHS Next Stage Review Final Support. TSO (The Stationery Office), 2008.

3 Department of Health. New Horizons: Towards a Shared Vision of Mental Health Consultation. Department of Health, 2009.

4 Royal College of Psychiatrists, Mental Health Network, NHS Confederation, London School of Economics and Political Science. Mental Health and the Economic Downturn: National Priorities and NHS Solutions (Occasional Paper OP70). Royal College of Psychiatrists, 2009.

5 Royal College of Psychiatrists. Looking Ahead: Future Development of UK Mental Health Services. Recommendations from a Royal College of Psychiatrists' Enquiry (Occasional Paper OP75). Royal College of Psychiatrists, 2010.

5 Appleby L. Offender health: the next frontier. Psychiatrist 2010; 34 409-10. 